\title{
ANALISIS BAURAN PEMASARAN TERHADAP PENJUALAN USAHA BAKERY (Studi Kasus pada Toko BreadTalk dan Kawan Baru Manado)
}

\section{Lourina Sondakh}

\begin{abstract}
The object of the research is Bakery shops in Manado. Bread Talk and Kawan Baru Bakery shop have chosen to be observed. The purpose of this study is to determine and to compare the marketing mix that is used by both bakery shops. The study is expected to provide input for bakery manufacturers in terms of management. From these results it can be concluded that the concept of marketing mix of Kawan Baru bakery shop is the selling concept that the output is profit while Bread Talk bakery shop is not only profit but also consumer satisfaction. The difference between the two stores is in the application of $4 P$ indicators which are product, price, place and promotion.
\end{abstract}

Keywords: Marketing Mix, Bakery Shops

\section{PENDAHULUAN}

\section{Latar Belakang}

Peranan sektor pertanian sangat penting bagi bangsa Indonesia karena sector ini mampu menyediakan lapangan pekerjaan, memasok pangan dan menyumbangkan devisa. Bauran pemasaran/Marketing mix harus selalu dapat bersifat dinamis, selalu dapat menyesuaikan diri dengan lingkungan eksternal maupun internal. Factor eksternal yaitu factor di luar jangkauan perusahaan yang antara lain terdiri dari pesaing, teknologi, peraturan pemerintah, keadaan perekonomian dan lingkungan social budaya. Sedangkan factor internal adalah variabel-variabel yang terdapat dalam bauran pemasaran/marketing mix yakni : Product (produk), Price (harga), Place (tempat), dan promotion (promosi).

Ketika para konsumen dihadapkan dengan banyak pilihan untuk setiap keputusan membeli yang mereka buat, kebutuhan para penjual adalah membangun hubungan yang kuat dengan para pelanggan. Pada kondisi pasar yang ramai saat ini, memahami persaingan dapat membedakan antara sukses dan gagal. Memberikan nilai yang tinggi kepada pelanggan saat ini merupakan kunci kesuksesan dalam persaingan pasar yang semakin meningkat (Lamb, Hair, Mcdaniel, 2001).

Usaha merupakan suatu kegiatan yang dilakukan oleh seorang atau sekelompok orang dengan tujuan untuk menghasilkan berbagai jenis ba- rang dan jasa yang dibutuhkan oleh masyarakat. Usaha meliputi kegiatan produksi, distribusi dan konsumsi.

Usaha bakery merupakan kegiatan ekonomi yang bertujuan untuk merubah bahan pangan/bahan baku pertanian untuk menjadi barang jadi (roti) agar memiliki nilai tambah. Selain itu, usaha bakery dapat memberikan keuntungan bagi produsen bakery/pengusaha bakery serta dapat memenuhi kebutuhan dan keinginan konsumen.

BreadTalk adalah jaringan took roti popular asal Singapura yang mempunyai cabang di Asia Tenggara dan Timur Tengah. Salah satu cabang yang ada di Indonesia adalah BreadTalk Cabang MegaMall Manado merupakan kerjasama antara George Quek (General Manager BreadTalk) dengan Johnny Andrean. BreadTalk didirikan di Indonesia pada tahun 2004, outlet BreadTalk yang pertama di Pondok Indah Mall Jakarta.

Kawan Baru didirikan sejak tahun 1995, pada awalnya Kawan Baru adalah usaha bakery kecil milik keluarga, Kawan Baru terus berkembang seiring berjalannya waktu, hingga saat ini Kawan Baru bisa berkembang sampai pada usaha restoran/kuliner, dan terus berkembang. Kawan baru telah memiliki cabang di Manado yaitu dua cabang bertempat di jalan Sam Ratulangi Boulevard (kawasan megamas Manado) dan satu cabang bertempat di Citra Land Winangun (water park). 


\section{Perumusan Masalah}

Berdasarkan latar belakang di atas, maka yang menjadi permasalahan dalam penelitian ini adalah bauran pemasaran apa yang digunakan oleh toko bakery BreadTalk dan Kawan Baru Manado.

\section{Tujuan dan Manfaat Penelitian}

Tujuan penelitian ini adalah untuk mengetahui dan membandingkan bauran pemasaran yang digunakan oleh toko bakery BreadTalk dan Kawan Baru Manado

Manfaat penelitian ini diharapkan dapat menjadi bahan masukan dan pertimbangan bagi produsen bakery dalam mengelola usaha bakery dan menjadi bahan referensi bagi penelitian selanjutnya.

\section{METODOLOGI PENELITIAN}

\section{Lokasi dan Waktu Penelitian}

Penelitian ini dilaksanakan selama tiga bulan, mulai dari bulan Mei 2010 sampai bulan Juli 2010. Dengan lokasi penelitian bertempat di Jalan Piere Tendean, Boulevard on Bisnis, Kawasan Mega Mas Manado. Tepatnya di took Bakery BreadTalk Manado dan Kawan Baru Manado.

\section{Metode Pengumpulan Data}

Penelitian ini merupakan penelitian studi kasus. Untuk pengambilan data primer yaitu, dengan menggunakan teknik wawancara berdasarkan daftar pertanyaan terhadap pemimpin kelompok tani dan anggota kelompok tani, sedangkan untuk data sekunder diperoleh dari instansi terkait seperti Kantor Desa Kolongan Kecamatan Kalawat.

\section{Metode Pengambilan Sampel}

Data yang digunakan dalam penelitian ini adalah data primer. Data primer diperoleh melalui wawancara dengan dua produsen bakery dan 50 sampel konsumen (khususnya konsumen yang pernah mengkonsumsi produk roti dari kedua bakery tersebut) yang dipilih secara spontan (accidental sampling).

\section{Konsep Pengukuran Variabel}

Adapun variabel-variabel yang akan diteliti dalam penelitian ini adalah:

1. Produk (product) adalah barang yang ditawarkan pada pasar sasaran. (cirri fisik produk:tampilan/kreasi, kemasan, merek dan rasa khususnya rasa roti coklat dan roti keju).

2. Harga (price) adalah sejumah uang yang harus dibayar konsumen untuk membeli suatu produk. (harga jual, tektik harga, strategi harga).

3. Tempat/saluran distribusi (place), menunjukan berbagai kegiatan yang dilakukan oleh took bakery untuk menjadikan produk dapat diperoleh dan tersedia bagi konsumen (jumlah outlet/took bakery, tampilan/desain outlet, tata ruang/letak outlet, fasilitas outlet/took bakery)

4. Promosi (promotion), merupakan bagian kegiatan yang dilakukan oleh took bakery untuk mengkombinasikan manfaat produk dan meyakinkan konsumen agar membelinya (media/alat promosi, periklanan/advertising, penjualan pribadi/personal selling, piblisitas/hubungan masyarakat, promosi penjualan).

\section{Metode Analisis Data}

Data yang diperoleh akan dianalisis secara deskriptif untuk mengetahui bauran pemasaran yang digunakan oeh kedua bakery tersebut.

\section{HASIL PENELITIAN DAN PEMBAHASAN}

\section{Deskripsi Tempat Penelitian}

\section{A. Toko Bakery BreadTalk}

BreadTalk Manado merupakan kerjasama antara George Quck (General Manager BreadTalk Singapura) dengan Johnny Andrean. BreadTalk Manado didirikan pada pertengahan tahun 2004. Konsepnya berbeda dibandingkan dengan tooktoko roti/bakery pad umumnya, dengan memperhatikan penampilan took yang dirancang agar terlihat eksklusif dengan menganut konsep seperti gallery dan dapurnya berkonsep seperti layaknya sebuah bengkel, jadi proses produksi dan pengolahan roti dapat dilihat langsung oleh konsumen melalui kaca transparan. 
BreadTalk Manado bertempat di Jalan Piere Tendean, Boulevard on Bisnis, Kawasan MegaMas, tepatnya di MegaMall Manado di depan pintu masuk, Ground floor.

Tabel 1. Tingkat Pendidikan Tenaga Kerja Pada Toko roti/bakery BreadTalk Manado

\begin{tabular}{|l|l|l|l|}
\hline No. & \multicolumn{1}{|c|}{ Jabatan } & \multicolumn{1}{|c|}{ Pendidikan } & $\begin{array}{l}\text { Banyaknya } \\
\text { Karyawan }\end{array}$ \\
\hline 1. & Manager Outlet & Strata 1 & 1 orang \\
\hline 2. & Store Manager & Diploma 3 & 2 orang \\
\hline 3. & $\begin{array}{l}\text { Ahli Tatabo- } \\
\text { ga/chef }\end{array}$ & $\begin{array}{l}\text { SMK/sederajat } \\
\text { Jur. Tataboga }\end{array}$ & orang \\
\hline 4. & Sales Counter & $\begin{array}{l}\text { SMK/sederajat } \\
\text { Jur. Tataboga }\end{array}$ & orang \\
\hline 5. & Kasir & $\begin{array}{l}\text { SMK/sederajat } \\
\text { Jur. Tataboga }\end{array}$ & orang \\
\hline 6. & $\begin{array}{l}\text { Cleanning Ser- } \\
\text { vice }\end{array}$ & SMA/sederajat & 2 orang \\
\hline \multicolumn{2}{|l|}{ Jumlah Tenaga Kerja } & 22 orang \\
\hline
\end{tabular}

Sumber data: data primer

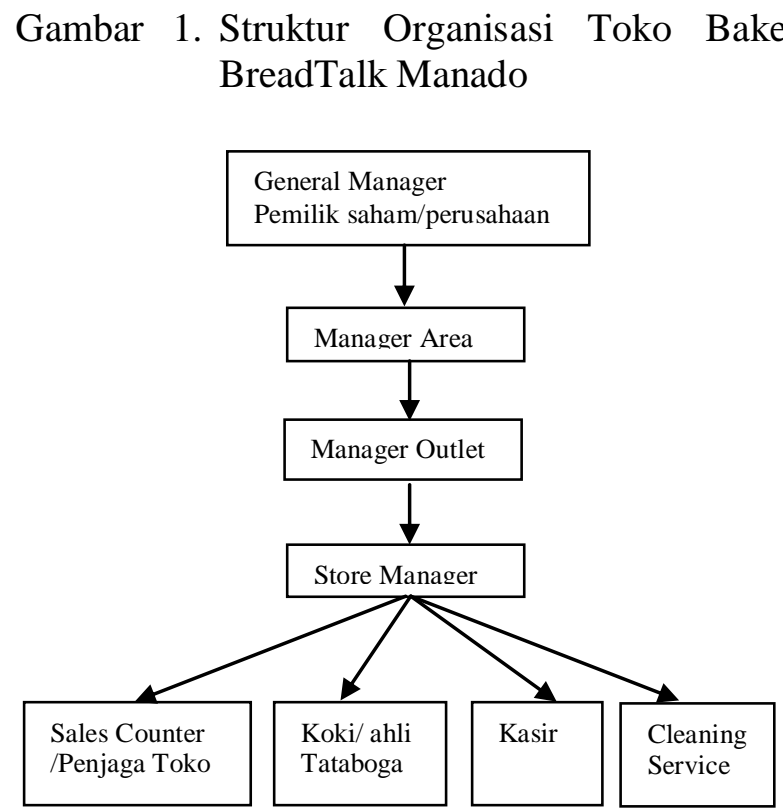

\section{B. Toko Bakery Kawan Baru}

Kawan Baru didirikan sejak tahun 1995. Pada awalnya Kawan Baru adalah sebuah usaha bakery berskala kecil milik keluarga.

Tabel 2. Tingkat Pendidikan Tenaga Kerja Pada Toko/bakery Kawan Baru Manado

\begin{tabular}{|l|l|l|l|}
\hline No. & \multicolumn{1}{|c|}{ Jabatan } & \multicolumn{1}{|c|}{ Pendidikan } & $\begin{array}{l}\text { Banyaknya } \\
\text { Karyawan }\end{array}$ \\
\hline 1. & Manager & Strata 1 & 2 orang \\
\hline 2. & $\begin{array}{l}\text { Ahli Tata- } \\
\text { boga }\end{array}$ & $\begin{array}{l}\text { SMK/Sederajat } \\
\text { Jur. Tataboga }\end{array}$ & 3 orang \\
\hline 3. & $\begin{array}{l}\text { Sales } \\
\text { Counter }\end{array}$ & SMA/SMK & 6 orang \\
\hline 4. & Kasir & SMA/SMK & 6 orang \\
\hline \multicolumn{2}{|l|}{ Jumlah tenaga kerja } & 17 orang \\
\hline
\end{tabular}

Sumber data: data primer

Gambar 2. Struktur Organisasi Toko Bakery Kawan Baru Manado

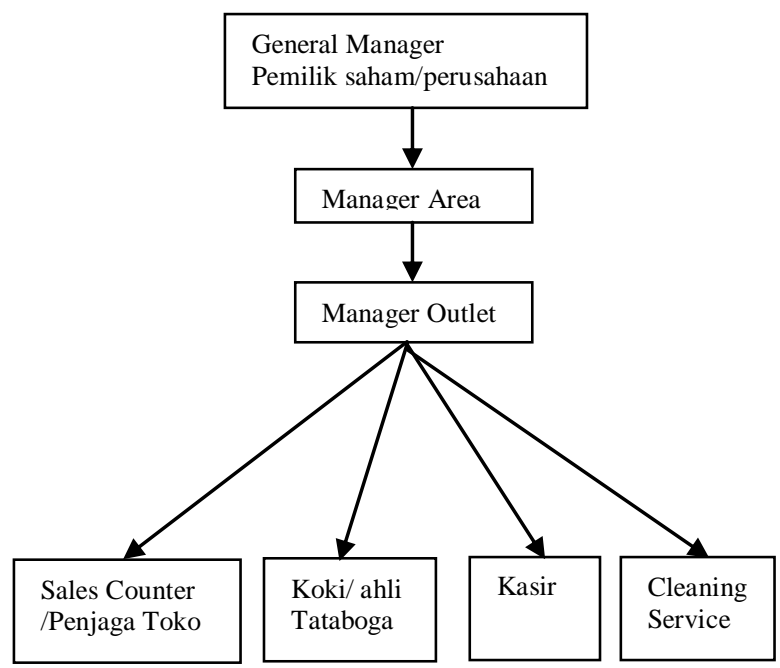

1.1.Bauran Pemasaran/Marketing Mix

Bauran pemasaran/marketing mix adalah variabel-variabel-variabel yang dapat dikendalikan oleh perusahaan, yang terdiri darei produk, harga, saluran distribusi dan promosi.

A. Analisis Bauran Pemasaran yang diterapkan pada toko bakery BreadTalk manado :

1) Merek sudah terkenal di seluruh Indonesia, bahkan diluar negeri.

2) Konsep took menyerupai gallery/butik dan dapur menyerupai bengkel (transparan)

3) Produk aman dikonsumsi karena ada izin dari BPOM dan DepKes

4) Aroma roti BreadTalk yang harum sehingga menarik perhatian konsumen 
5) Rasa roti yang enak dan meiliki cirri khas dari bakery lainnya

6) Kemasan roti menarik dan unik

7) Tenaga kerja ahli dibidangnya

8) Lokasi outlet yang strategis tepat ditempat keramaian/pusat perbelanjaan

9) Perusahaan berskala besar/internasional

10) Harga roti terjangkau untuk semua kalangan masyarkat/konsumen

11) Proses pembuatan kue menggunakan tenaga manusia juga mesin modern

B. Analisis Bauran Pemasaran yang diterapkan pada toko bakery Kawan Baru Manado :

1) Merek sudah terkenal di Manado

2) Konsep took roti dan caffe, bukan hanya menjual roti tapi juga menjual tempat/fasilitas untuk kepuasan konsumen (konsep produksi)

3) Rasa roti enak sehingga membuat konsumen tertarik untuk membelinya

4) Kemasan roti menarik

5) Harga roti terjangkau untuk semua kalangan masyarakat/konsumen

6) Pelayanan/costumer service memuaskan (menerima pesanan roti)

7) Terdapat 3 cabang outlet di Manado

8) Tenaga kerja ahli di bidangnya

9) Lokasi usaha yang strategis tepat ditengah keramaian/pusat perbelanjaan

10) Produk aman dikonsumsi karena memiliki izin dari BPOM dan DepKes

11) Proses pembuatan roti menggunakan tenaga manusia juga mesin modern

Table3. Deskripsi Bauran Pemasaran/Marketing Mix dari toko BreadTalk Manado dan Kawan Baru Manado

\begin{tabular}{|l|l|l|} 
Variabel & BreadTalk & Kawan baru \\
\hline
\end{tabular}

\begin{tabular}{|c|c|c|}
\hline \multicolumn{3}{|l|}{$\begin{array}{c}\text { Bauran pe- } \\
\text { masaran }\end{array}$} \\
\hline $\begin{array}{l}\text { Produk } \\
\text { - Tampilan/ }\end{array}$ & Unik dan mena- & Cukup \\
\hline - Kemasan & Unik dan mena- & $\begin{array}{l}\text { Unik dan me- } \\
\text { narik }\end{array}$ \\
\hline - Merek & $\begin{array}{l}\text { Berlisensi, ter- } \\
\text { kenal di LN }\end{array}$ & Terdaftar \\
\hline - Rasa & $\begin{array}{l}\text { Lezat dan mutu } \\
\text { tinggi } \\
\text { Aneka ragam }\end{array}$ & $\begin{array}{l}\text { Lezat dan } \\
\text { mutu tinggi }\end{array}$ \\
\hline 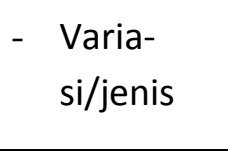 & $\begin{array}{l}\text { bentuk, tampi- } \\
\text { lan dan rasa }\end{array}$ & $\begin{array}{l}\text { Bentuk, tam- } \\
\text { pilan dan rasa } \\
\text { paten }\end{array}$ \\
\hline $\begin{array}{l}\text { Harga } \\
\text { - Harga jual } \\
\text { - Taktik } \\
\text { - Strategi }\end{array}$ & $\begin{array}{l}\text { Terjangkau } \\
\text { Tidak dite- } \\
\text { rapkan } \\
\text { Sudah dite- } \\
\text { rapkan }\end{array}$ & $\begin{array}{l}\text { Terjangkau } \\
\text { Tidak dite- } \\
\text { rapkan } \\
\text { Sudah dite- } \\
\text { rapkan }\end{array}$ \\
\hline $\begin{array}{l}\text { Tempat } \\
\text { - Jumlah } \\
\text { outlet }\end{array}$ & Tidak ada & \\
\hline $\begin{array}{l}\text { - Tampi- } \\
\text { lan/desain } \\
\text { outlet }\end{array}$ & $\begin{array}{l}\text { Menarik,seperti } \\
\text { konsep gallery } \\
\text { dan bengkel }\end{array}$ & $\begin{array}{l}\text { Menarik, in- } \\
\text { dah, modern }\end{array}$ \\
\hline Promosi & & \\
\hline - Periklanan & Iklan online & Iklan Online \\
\hline $\begin{array}{l}\text { - Penjualan } \\
\text { Pribadi }\end{array}$ & Tidak ada & Tidak ada \\
\hline $\begin{array}{l}\text { - Publisitas/ } \\
\text { humas }\end{array}$ & Tidak ada & Tidak ada \\
\hline $\begin{array}{l}\text { - Promosi } \\
\text { penjualan }\end{array}$ & Tidak ada & Tidak ada \\
\hline $\begin{array}{l}\text { - Situs je- } \\
\text { jaring so- } \\
\text { sial }\end{array}$ & $\begin{array}{l}\text { e-mail dan fa- } \\
\text { cebook }\end{array}$ & $\begin{array}{l}\text { e-mail dan } \\
\text { facebook }\end{array}$ \\
\hline
\end{tabular}

Dari data hasil penelitian ini, maka kita bisa melihat deskripsi dari bauran pemasaran yang telah diterapkan oleh kedua took bakery tersebut melalui table di atas, yaitu took bakery BreadTalk Manado lebih menitik beratkan strate- 
gi bauran pemasarannya pada variabel produk, lain halnya dengan toko bakery Kawan Baru yang lebih terfokus pada variabel tempa/saluran distribusi, sedangkan untuk variabel harga dan promosi kedua took bakery ini sama-sama menerapkan promosi online dan dengan harga jual yang terjangkau bagi seluruh kalangan masyarakat/konsumen.

Table 4. Atribut variabel-variabel bauran Pemasaran/Marketing Mix berdasarkan penilaian khusus

\begin{tabular}{|c|c|c|c|c|c|c|}
\hline \multirow{2}{*}{$\begin{array}{c}\text { Variabel Bauran } \\
\text { Pemasaran }\end{array}$} & \multicolumn{3}{|c|}{ BreadTalk } & \multicolumn{3}{|c|}{ Kawan Baru } \\
\hline & 1 & 2 & 3 & 1 & 2 & 3 \\
\hline \multirow{3}{*}{$\begin{array}{l}\text { Produk } \\
\text { - Tampilan/kreasi } \\
\text { - Kemasan } \\
\text { - Rasa }\end{array}$} & $\sqrt{ }$ & & & & $\sqrt{ }$ & \\
\hline & $\sqrt{ }$ & & & $\sqrt{ }$ & & \\
\hline & $\sqrt{ }$ & & & & $\sqrt{ }$ & \\
\hline $\begin{array}{l}\text { Harga } \\
- \text { Harga jual }\end{array}$ & & & $\sqrt{ }$ & & $\sqrt{ }$ & \\
\hline \multirow{4}{*}{$\begin{array}{l}\text { Tempat } \\
\text { - } \text { Kenyamanan } \\
\text { outlet } \\
\text { - } \text { Tampilan/desain } \\
\text { outlet } \\
\text { - } \text { Letak/tataruang } \\
\text { outlet } \\
\text { - } \text { Fasilitas outlet } \\
\end{array}$} & & & $\sqrt{ }$ & $\sqrt{ }$ & & \\
\hline & $\sqrt{ }$ & & & $\sqrt{ }$ & & \\
\hline & $\sqrt{ }$ & & & $\sqrt{ }$ & & \\
\hline & & & $\sqrt{ }$ & $\sqrt{1}$ & & \\
\hline \multirow{2}{*}{$\begin{array}{l}\text { Promosi } \\
\text { - Iklan online } \\
\text { - billboard }\end{array}$} & $\sqrt{ }$ & & & $\sqrt{ }$ & & \\
\hline & $\sqrt{ }$ & & & $\sqrt{ }$ & & \\
\hline
\end{tabular}

Keterangan :

1. Menarik/lezat/murah/nyaman/strategis/memuaskan.

2. Cukup/biasa saja.

3. Tidak menarik/tidak lezat/mahal/tidak nyaman/tidak strategis/tidak memuaskan.

Tabel 5. Jumlah Produksi Roti pada took bakery BreadTalk Manado dan Kawan Baru Manado per hari

\begin{tabular}{|c|c|c|}
\hline $\begin{array}{c}\text { Variabel yang dite- } \\
\text { liti }\end{array}$ & $\begin{array}{c}\text { BreadTalk } \\
\text { (item/hari) }\end{array}$ & $\begin{array}{c}\text { Kawan Baru } \\
\text { (item/hari) }\end{array}$ \\
\hline Roti Coklat & 1000 & 750 \\
\hline Roti Keju & 1000 & 750 \\
\hline
\end{tabular}

Tabel 6. Persentase jumlah permintaan pada toko bakery BreadTalk Manado dan Kawan Baru Manado

\begin{tabular}{|c|c|c|c|}
\hline No. & Hari Kerja & $\begin{array}{c}\text { Bread } \\
\text { Talk } \\
(\%)\end{array}$ & $\begin{array}{c}\text { Kawan } \\
\text { Baru } \\
(\%)\end{array}$ \\
\hline 1. & Senin - Jumat & 90 & 90 \\
\hline
\end{tabular}

\begin{tabular}{|c|c|c|c|}
\hline 2. & Sabtu - Minggu & $90-100$ & $95-100$ \\
\hline 3. & Hari libur/hari raya & $95-100$ & $95-100$ \\
\hline 4. & Jika ada pesanan & 85 & 90 \\
\hline
\end{tabular}

Sumber data: data primer

Menurut data table di atas, permintaan took bakery BreadTalk biasanya melonjak pada harihari libur atau saat akhir pecan, sedangkan pesanan roti dari konsumen jarang, namun laian halnya dengan took bakery Kawan Baru, permintaan melonjak pada saat hari libur/akhir pecan dan permintaan lebih tinggi pada saat ada pesanan roti dari konsumen.

\subsection{Produk (product)}

a. Toko bakery BreadTalk Manado :

Salah satu tugas utama dan tanggungjawab bidang manajemen pemasaran adalah memikirkan desain produk. Bagian pemasaran seolah-olah bertugas sebagai mata perusahaan yang harus selalu jeli dalam mengamati kebutuhan konsumen. Mereka yang ada di bagian ini harus secara terus menerus memberikan saran, perbaikan atau perubahan desain produk yang disesuaikan dengan keinginan pembeli. Dari sinilah dapat dihasilkan produk yang benar-benar baru bagi perusahaan atau hanya sekedar modifikasi dari produk yang sudah ada.

Produk adalah sesuatu yang ditawarkan kepada konsumen untuk memuaskan suatu kebutuhan dan keinginan. Dalam penelitian ini penerapan strategi pemasaran yang digunakan oleh took bakery BreadTalk Manado sudah cukup baik karena selalu berorientasi pada pemenuhan kebutuhan dan keinginan konsumen, jadi bukan hanya sekedar menghasilkan produk dan berperan sebagai penjual, namun melalui produknya BreadTalk juga turut menyalurkan jasanya berdasarkan permintaan, keinginan dan kebutuhan konsumennya. Beberapa srategi produk yang diterapkan oleh bakery ini seperti tampilan/kreasi/hiasan pada roti BreadTalk dibuat semenarik mungkin dengan rasa dan warna yang menggugah selera, sehinga bila hanya dilihat sekilas saja produk BreadTalk mampu menarik perhatian konsumen. Selain itu, produk BreadTalk bukan hanya dapat memenuhi kebutuhan jasmani konsumennya melainkan juga kebuthan rohani konsumen yakni nilai kepuasan 
melalui cirri fisik produk tersebut. Adapun pada saat-saat tertentu BreadTalk akan memproduksi produk terbaru yang sesuai dengan kondisi lingkungan sekitar perusahan, contohnya saat digelar Piala Dunia 2010, BreadTalk memproduksi roti coklat berbentuk bola yang dihiasi coklat dan coklat putih di atasnya. Selain itu, BreadTalk mempunyai 1 jenis roti andalan yang merupakan cirri khas roti BreadTalk yaitu roti abon rasa daging, roti jenis ini banyak ditiru oleh bakery lain namun rasanya tetap berbeda karena roti abon BreadTalk memiliki citarasa khusus yang sulit ditiru oleh bakery-bakery pesaingnya. Menurut data-data yang diperoleh dalam penelitian ini, maka konsep pemasaran dari toko roti BreadTalk Manado sudah sangat baik karena selalu memperhatikan kebutuhan dan keinginan konsumen serta faktor-faktor lain/eksternal yang bisa saja terjadi dan mengalami perubahan yang sangat cepat yang takdapat dikendalikan oleh perusahaan. Jadi, dari hasil penelitian ini toko bakery BreadTalk Manado dapat dikategorikan sebagai perusahaan yang menganut konsep pemasaran yang hasil akhirnya bukan hanya bertujuan untuk memperoleh laba, namun selain itu juga perusahaan ini bertujuan untuk memperoleh hasil akhir berupa kepuasan dari para konsumennya.

\section{b.Toko bakery Kawan Baru Manado}

Produk dapat berupa barang dan jasa maupun ide-ide. Istilah lain yang sering digunakan untuk produk adalah penawaran atau solusi, misalnya sebuah toko roti/bakery menawarkan barangbarang (seperti roti, cake, soft drink), jasa-jasa (seperti pembelian, memasak, tempat duduk), ideide (seperti alternative tempat santai yang dapat memenuhi kebutuhan jasmani maupun rohani masyarakat). Manufaktur seringkali melakukan kesalahan dengan lebih memperhatikan produk secara fisik daripada jasa-jasa yang dihasilkan oleh produk-produk tersebut. Mereka lebih memandang diri mereka sebagai penjual produk daripada memberikan solusi terhadap suatu kebutuhan. Padahal produk secara fisik sebenarnya merupakan sarana untuk menyampaikan jasa-jasa kepada kita. Pekerjaan pemasar sebenarnya adalah untuk menjual benefit atau jasa melalui produk fisik da- ripada hanya sekdar menonjolkan cirri-ciri fisik suatu produk (kemasan, rasa, tampilan, merek, kwalitas dan kwantitas bahan baku).

Dalam penelitina ini, toko bakery Kawan Baru Manado tidak menitik beratkan strategi bauran pemasarannya kepada produknya karena tampilan serta kreasi roti Kawan Baru disajikan dalam bentuk, ukuran dan rasa yang paten tanpa ada perubahan desain produk, dalam hal initoko roti $\mathrm{Ka}-$ wan Baru dapat disebut perusahaan yang menganut konsep "Marketing Myiopia" yaitu perusahaan hanya terfokus pada satu sasaran yakni hanya pada cirri fisik produk tanpa memperhatikan kebutuhan dan keinginan konsumen. Toko bakery Kawan Baru hanya melakukan strategi penjualan yang input akhirnya adalah perolehan laba melalui volume penjualan. Untuk itu, kegiatan pemasaran di took bakery Kawan Baru harus terus dikembangkan agar mampu bertahan dalam menghadapi persaingan pasar yang semakin global dan modern serta perlu banyak menginput informasi-informasi terbaru mengenai perkembangan dan teknik-teknik/strategi pemasaran usaha bakery.

\subsection{Harga (Price)}

Harga merupakan salah satu bagian yang sangat penting dalam pemasaran suatu produk karena harga adalah salah satu dari empat bauran pemasaran/marketing mix. Harga, juga merupakan penentu keberhasilan suatu perusahan, karena harga menentukan seberapa besar keuntungan yang akan diperoleh oleh perusahan dari penjualan produknya baik berupa barang maupun jasa.

Dalam penelitian ini, kedua bakery samasama menggunakan strategi penetapan harga berdasarkan pendekatan biaya, yaitu berdasarkan besar kecilnya biaya yang dikeluarkan oleh perusahaan, sehingga bila terjadi kenaikan bahan baku kedua toko bakery akan mensiasati hal tersebut dengan menurunkan sedikit stok bahan baku tanpa disadari oleh konsumen. Kemudian bahan baku akan disesuaikan lagi apabila harga bahan baku normal kembali. Table 7. di atas menunjukan bahwa persentase penilaian konsumen tertinggi mengenai atribut kenyamanan outlet adalah toko roti/bakery Kawan Baru Manado sebesar 64\%, 
dan untuk toko roti/bakery BreadTalk Manado mencapai nilai sebesar $28 \%$. Sedangkan persentase penilaian konsumen tertinggi mengenai atribut kelezatan produk roti dari masing-masing toko roti/bakery didominasi oleh toko roti/bakery BreadTalk Manado sebesar $72 \%$, dan untuk took roti Kawan Baru Manado mencapai nilai sebesar $36 \%$.

Table 7. Atribut dan Harga roti di toko roti/bakery breadTalk dan Kawan Baru Manado berdasarkan persentase Penilaian Konsumen

\begin{tabular}{|c|c|c|c|c|c|c|}
\hline \multirow[b]{2}{*}{ No } & \multirow{2}{*}{$\begin{array}{c}\text { Toko } \\
\text { Ro- } \\
\text { ti/Bakery }\end{array}$} & \multicolumn{2}{|c|}{$\begin{array}{l}\text { Harga Roti } \\
\text { (Rp) }\end{array}$} & \multicolumn{2}{|c|}{ Atribut (\%) } & \multirow{2}{*}{$\begin{array}{c}\text { Jumlah } \\
\text { Persen- } \\
\text { tase }\end{array}$} \\
\hline & & $\begin{array}{c}\text { Cok- } \\
\text { lat }\end{array}$ & Keju & $\begin{array}{l}\text { Kenya- } \\
\text { manan }\end{array}$ & $\begin{array}{l}\text { kele- } \\
\text { zatan }\end{array}$ & \\
\hline 1. & BreadTalk & 8000 & 7000 & 28 & 72 & 100 \\
\hline 2. & $\begin{array}{c}\text { Kawan } \\
\text { Baru }\end{array}$ & 5500 & 5500 & 64 & 36 & 100 \\
\hline
\end{tabular}

Sumber data: data primer

\subsection{Tempat/saluran Distribusi (Place)}

Tempat/saluran distribusi merupakan masalah lain yang akan dihadapi oleh perusahaan pada saat produk selesai diproses. Saluran distribusi menyangkut cara penyampaian produk ke tangan konsumen. Manajemen pemasaran mempunyai peranan dalam mengevaluasi penampilan para penyalur, bila perusahaan merencanakan suatu pasar tertentu, yang pertama kali dipikirkan adalah siapa yang akan ditunjuk sebgai penyalur di sana, atau berapa yang bersedia untuk menjadi penyalur di daerah itu.

Ada beberapa faktor yang harus diperhatikan sebelum menentukan distribusi yang akan digunakan, diantaranya adalah jenis produk, kemampuan perusahaan, dan sebagainya. Untuk itu dalam penelitian ini kedua toko bakery tersebut sama-sama memilih tempat yang strategis sebagai saluran distribusinya, tepatnya terletak dipusat perbelanjaan dimana tempat tersebut sangat ramai dikunjungi oleh masyarakat, baik pada hari biasa maupun pada hari libur. Namun, dari hasil survey oleh peneliti bahwa ada sedikit keunggulandari salah satu bakery yakni Kawan Baru yang menggunakan strategi persaingan melalui saluran distribusi yang disebarkan pada beberapa tempat, untuk lebih mempermudah kegiatan distribusi dan penjualan produknya. Selain menyediakan $3 \mathrm{ca}-$ bang, toko roti/bakery Kawan Baru juga melengkapi outlet rotinya dengan beberapa fasilitas, seperti jaringan internet gratis bagi para konsumen yang berkunjung, juga tersedia televise untuk konsumen yang ingin berbelanja sambil menonton TV, serta musik-musik yang bisa menghibur konsumennya yang sedang berbelanja roti ataupun yang sedang menikmati roti dari Kawan $\mathrm{Ba}-$ ru. Sedangkan toko roti/bakery BreadTalk Manado tidak membukan cabang ditempat lain karena menurut hasil pemantauan dari bagian pemasarannya, bahwa daya beli masyarakat Manado masih kurang sehingga pihak manajemen hanya memusatkan saluran distribusinya pada satu lokasi saja yang dianggap strategis dan bisa dijangkau oleh seluruh kalangan masyarakat.

\subsection{Promosi (Promotion)}

Promosi adalah salah satu bagian dari bauran pemasaran yang besar peranannya. Promosi merupakan suatu ungkapan dalam arti luas tentang kegiatan-kegiatan yang secara aktif dilakukan oleh perusahaan (penjual) untuk mendorong konsumen membeli produk yang ditawarkan.

Bauran promosi terdiri dari 5 unsur utama (P. Kotler, 2000), yaitu periklanan, penjualan pribadi, hubungan masyarakat/publisitas, pemasaran langsung, serta promosi penjualan.

Adapun kegiatan-kegiatan promosi yang dilakukan oleh toko roti/bakery BreadTalk dan Kawan Baru Manado, yaitu :

- Direct mail : e-mail, facebook, tweeter

- Iklan online

- Billboard

- Poster

- Telephone selling/penjualan melalui telepon

Dalam penelitian ini, masing-masing toko bakery melakukan kegiatan promosi yang berorientasi pada faktor-faktor internal maupun eksternal. Salah satu contohnya promosi yang telah dilakukan oleh toko roti/bakery Kawan Baru berdasarkan kondisi lingkungan sekitar perusahaan, yakni pada saat moment Piala Dunia 2010 toko Kawan Baru mengadakan promosi melalui kegiatan nonton bareng, hal ini bertujuan selain untuk meme- 
nuhi kepuasan konsumen, juga untuk meningkatkan kunjungan konsumen. Lain halnya dengan took roti/bakery BreadTalk Manado pada saat atu momen yang bersamaan telah memproduksi produk terbarunya berupa produk khusus roti coklat berbentuk bola yang ditaburi coklat dan coklat putih di atasnya. Hal ini dilakukan untuk menarik perhatian para konsumen agar membeli produknya sekaligus mengingatkan kembali kepad para konsumen akan produk lama lainnya masih tersedia dengan rasa dan kwalitas yang tidak berubah, serta memuaskan kebutuhan dan keinginan konsumen pada saat itu sedang menyambut pertandingan sepak bola Piala Dunia 2010.

\section{KESIMPULAN DAN SARAN}

\section{Kesimpulan}

Berdasarkan hasil penelitian dapat disimpulkan bahwa :

1. Bauran pemasaran yang diterapkan oleh toko bakery Kawan Baru Mando menitikberatkan pada keuntungan/laba melalui volume penjualan, sedangkan pada toko bakery BreadTalk Manado menitikberatkan pada kepuasan konsumen.

2. Produk, bakery BreadTalk memiliki brand image/nama perusahaan yang sudah terkenal kualitasnya dibandingkan bakery Kawan Baru Manado.

3. Harga bakery BreadTalk relatif lebih mahal dibandingkan bakery Kawan Baru.

4. Tempat, toko bakery BreadTalk Manado memilih satu tempat usaha yang letaknya strategis sedangkan toko bakery Kawan Baru Manado mendekati konsumen dengan membuka beberapa cabang.

5. Promosi, bakery Kawan Baru Manado memiliki fasilitas outlet berupa jaringan wifi, live musik dan televisi, sedangkan toko bakery BreadTalk tidak menyediakan fasilitas outlet.

\section{Saran}

1. Toko bakery Kawan Baru Manado disarankan agar merubah ciri fisik produk menjadi lebih menarik dan unik serta memiliki beberapa jenis, bentuk, kreasi sesuai selera konsumen.
2. Harga bakery Kawan Baru dapat dinaikkan dengan meningkatkan kualitas dan citarasa dengan tetap mempertahan prinsip harga bersaing.

3. Toko bakery Kawan Baru Manado tetap mempertahankan pelayanan konsumen melalui fasilitas outlet, sedangkan toko bakery BreadTalk Manado sebaiknya menyediakan fasilitas outlet berupa tempat duduk, jaringan wifi, televisi, live music maupun menambah cabang untuk perluasan pasar dan lokasinya mudah dijangkau konsumen.

4. Pengaruh bauran pemasaran terhadap penjualan belum dianalisis dalam penelitian ini. Penelitian lanjutan untuk mengetahui pengaruh bauran pemasaran terhadap keuntungan usaha bakery kedua toko tersebut perlu dilakukan.

\section{DAFTAR PUSTAKA}

Angipora, Maskus P,1999. Dasar-dasar Pemasaran.edisi I cetakan 1, PT. Raja Grafindo Persada, Jakarta.

Bilson Simamora, 2008. Panduan Riset Perilaku Konsumen. PT. Gramedia Pustaka Utama, Jakarta.

Firdaus, Muhammad, 2009. Manajemen Agribisnis. Cetakan Kedua. Bumi Aksara JaKARTA

Lamb C. W. Hair J.F. Mcdaniel Carl, 2001. Pemasaran. PT Salemba emban Patria, Jakarta.

Lingg P.C.M.MM.2004 Strategic Marketing Plan. PT. Gramedia Pustaka Utama, Jakarta.

Limbong, W $>\mathrm{H}$ dan P.Sitorus,2007. Pengantar Tataniaga Pertanian Jurusan Ilmu-ilmu Sosial Ekonomi, Jakarta.

M.Suyanto,2007.Marketing Strategy.Top Brand Indonesia.C.V. Andi Offset, Yogyakarta.

Nugroho, J.Setiadi, SE, MM,2008. Perilaku Konsumen: Konsep dan Implikasi untuk Strategy dan Penelitian Pemasaran. Kencana Prenada Media Group, Jakarta.

P.Kotler,A.B.Susanto.2000.Manajemen Pemasaran di Indonesia,Buku 2.Salemba, Jakarta. 
Tjiptono,F,2004.Pemasaran Jasa.Bayu Media, Malang.

Panji,Anoraga,SE,MM,2009.Manajemen Bisnis.Cetakan keempat.PT. Rineka Cipta, Jakarta.

Payne,A.2000.Service Marketing Pemasaran Jasa.Andi dan Pearson Education Asia Pte.Ltd Yogyakarta.

Skinner,Steven J.Ivancevich,Jhon M,1992. Business for the $21^{\text {st }}$ century. Home Wood:Irwin.

Suyanto,M,2007. Marketing Strategy. Andi offset, Yogyakarta.

Swastha Basu dan Irawan,2000.Manajemen Pemasaran Modern.Liberty,Yogyakarta. 
